ISSN: $1412-8837$

\title{
ANALISIS KELAYAKAN FINANSIAL USAHATANI KOPI ARABIKA DI DESA BANDUNG BARU KECAMATAN KABAWETAN KABUPATEN KEPAHIANG
}

\author{
(FINANCIAL FEASIBILITYANALYSIS OF FARM ARABICA COFFEE IN \\ DESA BANDUNG BARU, SUB-DISTRICT KABAWETAN, KEPAHIANG \\ REGENCY)
}

\author{
Siska Sri Wahyuni, Satria Putra Utama, Gita Mulyasari \\ Jurusan Sosial Ekonomi Pertanian Fakultas Pertanian Universitas Bengkulu
}

\begin{abstract}
The research was conducted in Desa Bandung Baru, Subdistrict Kabawetan Kepahiang Regency Bengkulu Province. The purpose of this study were: 1) To Analyze the financial feasibility of arabica coffee farm in village of Bandung Baru subdistrict Kabawetan Kepahiang regency Bengkulu Province from the financial aspect, 2) To Calculate the payback period and the level of sensitivity against the declaine in Arabica coffee farm production, price reductions, increased investment costs, operating costs and maintenance. Determination of respondent carried out using Stratified Random Sampling, data consist of primary data and secondary data. The number of respondent in this study were 40 samples. The results of this study indicate that the views of financial aspects of Arabica coffee farm worth the effort, this is apparent from the Net B/C is 2,17 (>1), Gross B/C value is $1,28(>1), P V^{\prime \prime} / K$ value is 2,11 (>1), NPV of Rp. 18.847.733 and IRR value is $26,60 \%$. Sensitivity analysis shows that if there was increase in production $29 \%$, price of production decreased $22 \%$ and decrease production $22 \%$.
\end{abstract}

Keywords: arabica coffee farming, financial feasibility analysis, sensitivity analysis

\section{PENDAHULUAN}

Tingkat pertumbuhan perekonomian Indonesia di bidang non pertanian (industri) dan migas mengalami penurunan yang cukup tajam. Hal ini dimulai pada saat Indonesia mengalami krisis moneter yang mengakibatkan nilai tukar rupiah terhadap dolar merosot tajam. Akibatnya para pengusaha pada bidang tersebut gulung tikar. Dengan keadaan seperti ini maka Indonesia tidak dapat berharap banyak pada sektor non pertanian (industri) atau migas. Untuk mengantisipasi keadaan tersebut maka pemerintah beralih pada bidang usaha 
pertanian untuk menjalankan roda perekonomian di Indonesia yang dianggap memiliki prospek dan tidak rentan (tahan) terhadap gejolak perekonomian (krisis moneter). Salah satu subsektor pertanian yang cukup menonjol dan memiliki peluang untuk dikembangkan yaitu perkebunan. Tanaman perkebunan tumbuh subur dan diusahakan secara intensif oleh para pengusaha agribisnis indonesia. Sektor pertanian memiliki peranan penting dalam perekonomian nasional ini ditandai oleh kontribusinya yang dominan, baik dalam Produk Domestik Bruto sebesar 23,4\%, maupun dalam lapangan pekerjaan sebanyak $54 \%$ kaitan inilah, sektor pertanian selalu menjadi prioritas dalam pembangunan bidang ekonomi.

Desa Bandung Baru merupakan salah satu desa di Kecamatan Kabawetan yang membudidayakan kopi arabika, dibandingkan dengan desa lainnya. Maka dengan melihat kenyataan ini peneliti tertarik untuk meneliti apakah Usahatani Kopi Arabika yang dibudidayakan oleh petani di Desa Bandung Baru layak dilihat dari aspek finansial.

Berdasarkan masalah di atas, tujuan yang ingin dicapai dalam penelitian ini, adalah : 1) Menganalisis tingkat kelayakan finansial usahatani kopi arabika selama umur ekonomis di Desa Bandung Baru Kecamatan Kabawetan Kabupaten Kepahiang. 2)Menghitung nilai payback period dan tingkat kepekaaan (sensitivitas) usahatani kopi arabika terhadap penurunan produksi, penurunan harga jual, kenaikan biaya investasi, biaya operasional dan pemeliharaan di Desa Bandung Baru Kecamatan Kabawetan Kabupaten Kepahiang.

\section{METODE PENELITIAN}

\section{Metode Penentuan Lokasi}

Penentuan lokasi dilakukan secara sengaja (purposive) yaitu di Desa Bandung Baru Kecamatan Kabawetan Kabupaten Kepahiang Provinsi Bengkulu. Lokasi ini dipilih dengan pertimbangan bahwa desa tersebut merupakan salah satu sentra penghasil kopi di Kecamatan Kabawetan. Selain itu umur tanaman kopi yang diusahakan oleh para petani bervariasi mulai dari 0 tahun sampai 10 tahun, sehingga tujuan penelitian tercapai.

\section{Metode Penentuan Responden}

Responden dalam penelitian ini adalah petani yang mengusahakan tanaman kopi. Populasi petani kopi arabika sebanyak 102 petani, diambil berdasarkan pertimbangan adanya perbedaan umur tanaman. Adapun penentuan responden dilakukan dengan tehnik Stratified Random Sampling dengan strata umur kopi arabika, dimana dari 102 populasi yang diambil sebagai sampel adalah sebanyak 40 petani. Dalam hal ini petani dikelompokkan menjadi 4 kelompok. Kelompok pertama adalah 6 petani kopi yang memiliki 
umur 0 -1 tahun, kelompok kedua adalah 10 petani kopi yang memiliki umur 2 4 tahun, kelompok ketiga adalah 14 petani kopi yang memiliki umur 5 - 7 tahun , dan kelompok keempat adalah 10 petani kopi yang memiliki umur 8 - 10 tahun.

Tehnik pengambilan responden yang digunakan untuk setiap strata adalah secara stratified random sampling, karena jumlah populasi bervariasi maka rumus yang akan digunakan untuk pengambilan sampel ini adalah metode alokasi Neyman, Sheaffer et al (1990) yaitu:

$$
n_{i}=n\left(\frac{N_{i} \sigma_{i}}{\sum_{i=1}^{L} N_{i} \sigma_{i}}\right) \quad n=\frac{\left(\sum_{i=1}^{L} N_{i} \sigma_{i}\right)^{2}}{N^{2} D+\sum_{i=1}^{L} N_{i} \sigma_{i}^{2}}
$$

dimana : N: Jumlah Populasi ( $\left.\mathrm{N}_{1}: 14, \mathrm{~N}_{2}: 34, \mathrm{~N}_{3}: 36, \mathrm{~N}_{4}: 18\right)$, n: Jumlah sampel (n: 40), $\sigma: \operatorname{Varian}\left(\sigma_{1}: 0.4322 ; \sigma_{2}: 0.3081 ; \sigma_{3}: 0.4199 ; \sigma_{4}: 0.5832\right), \mathrm{i}:$ Strata $(1,2,3,4), \mathrm{D}$ : Bound of error $(0.000625), \mathrm{n}_{1}: 6, \mathrm{n}_{2}: 10, \mathrm{n}_{3}: 14$, dan $\mathrm{n}_{4}: 10$.

Setelah jumlah sampel diketahui, maka pemilihan responden dilakukan secara acak (random) dengan memperhatikan keragaman atribut yang ada, sehingga dapat memberikan informasi yang mewakili kondisi nyata di daerah penelitian.

\section{Metode Pengumpulan Data}

Data yang dikumpulkan adalah data-data primer dan data-data sekunder. Data primer diperoleh dari pengamatan langsung di lapangan dan dari hasil wawancara kepada responden. Wawancara dipandu dengan menggunakan kuisioner (daftar pertanyaan yang telah disiapkan sebelumnya).

Data sekunder diperoleh dari berbagai lembaga dan instansi yang terkait dengan permasalahan yang diteliti, yakni Dinas Perkebunan Kabupaten Kepahiang, Badan Pusat Statistik, dan Dinas Penyuluhan Kehutanan dan Perkebunan, Lembaga Desa yang terkait (kantor Kepala Desa) serta penelitianpenelitian terdahulu yang ada kaitannya dengan permasalahan yang sedang dikaji. Data-data sekunder tersebut berupa data jumlah populasi petani usahatani kopi arabika, data kisaran produksi kopi umur tanaman 0-10 tahun.

\section{Metode Analisis Data}

Metode yang digunakan dalam penelitian Kelayakan Usahatani Kopi Arabika ini bersifat nilai kini (present value) karena bersumber dari data pada saat penelitian berlangsung. Asumsi-asumsi yang digunakan adalah sebagai berikut: 
i. Data yang digunakan adalah data di lokasi penelitian. Data primer ataupun data sekunder yang diambil pada saat melakukan penelitian di desa Bandung Baru.

ii. Biaya dan manfaat merupakan nilai kini. Nilai yang berlaku dipasaran pada tahun dilakukannya penelitian.

iii. Umur ekonomis kopi arabika 0 - 10 tahun. Umur ekonomis ini dilihat dari data yang didapatkan pada saat melakukan penelitian melalui data primer berupa kuisioner dan data sekunder yang didapatkan dari kepala desa. Hal ini juga diperkuat oleh hasil penelitian sebelumnya di daerah Kabupaten Karo Provinsi Sumatera Utara yang mengatakan umur ekonomis atau masa berproduksi kopi arabika selama 10 tahun (Hosanna, 2009)

iv. Hargajual yang berlakuharga pada tahun 2011

v. Harga input yang berlakuharga pada tahun 2011

vi. Discount Factor yang digunakan $14 \%$, untuksuku bunga Bank yang berlaku pada saat ini dan DF ini khusus bunga bank pengkreditan dalam bidang perkebunan rakyat

Adapun penilaian kelayakan usahatani kopi arabika untuk data primer dari lapangan dan data pustaka menurut Gittinger (1986), Gray dkk (1993) adalah sebagai berikut :

1. Net Benefit Cost Ratio(Net B/C)

2. Gross Benefit Cost Ratio (Gross B/C)

3. Profitability Ratio $\left(\mathrm{PV}^{\prime \prime} / \mathrm{K}\right)$

4. Net Present Value (NPV).

5. Internal Rate of Return (IRR)

\section{HASIL DAN PEMBAHASAN}

\section{Kriteria Investasi}

Didalam analisis finansial terdapat kriteria - kriteria yang harus dipenuhi antara lain : Net B/C Ratio, Gross B/C Ratio, NVP, IRR dan profitability. Didalam penelitian ini tingkat suku bunga yang digunakan adalah tingkat suku bunga yang sedang berlangsung dan pada saat penelitian berlangsung tingkat suku bunga atau discount rate yaitu sebesar $14 \%$. Berdasarkan hasil penelitian di Desa Bandung Baru dapat diketahui besarnya nilai dari masing - masing kriteria investasi dapat dilihat di Tabel 1. 
Tabel 1. Perincian Kelayakan Investasi Usahatani Kopi Arabika di Desa Bandung Baru Kecamatan Kabawetan Kabupaten Kepahiang selama 10 tahun.

\begin{tabular}{clrlr}
\hline No & \multicolumn{1}{c}{ Uraian } & \multicolumn{1}{c}{ Total } & \multicolumn{1}{c}{ Kriteria } & \multicolumn{1}{c}{ Nilai } \\
\hline 1 & Benefit kotor & 180.411 .667 & Net B/C Ratio & 2,18 \\
2 & Biaya (Cost) & 128.766 .734 & Gross B/C Rati & 1,28 \\
3 & DF 14 \% & 6.21 & Profitability & 2,11 \\
4 & Investasi & 18.849 .657 & NVP & 18.847 .733 \\
5 & O\&M & 109.917 .077 & IRR & $26,60 \%$ \\
6 & PV Gross B & 85.849 .588 & & \\
7 & PV Gross C & 67.001 .856 & \\
8 & PV Net B-C (+) & 34.886 .667 & \\
9 & PV Net B-C (-) & 16.038 .935 & \\
10 & Benefit Bersih & 51.644 .933 & \\
11 & DF 13\% & 6.42 & \\
12 & PV B-C 14\% & 18.847 .733 & \\
13 & PV B-C 13\% & 20.343 .291 & \\
14 & PVGr (B-OM) & 35.818 .074 & & \\
15 & PV Invest & 16.970 .341 & \\
\hline
\end{tabular}

Sumber : Hasil Olahan Data Primer

\section{Net B/C Ratio}

Berdasarkan Tabel 1, besarnya PV positif yaitu Rp. 34.886.667 PV negatif Rp. 16.038.935 sehingga didapatkan dari hasil Net B/C Ratio sebesar 2.18yang berarti untuk satu Rupiah yang diinvestasikan akan memberikan manfaat sebesar2.18 Rupiah atau dengan kata lain manfaat yang diperoleh sebesar 2.18 kali lipat dari biaya yang dikeluarkan. Dimana nilai tersebut lebih besar dari satu (>1) maka Usahatani Kopi Arabika di Desa Bandung Baru Kecamatan Kabawetan Kabupaten Kepahiang Layak untuk diusahakan karena dapat memberikan keuntungan atas investasi yang ditanamkan

\section{Gross B/C Ratio}

Berdasarkan Tabel 1 dengan tingkat Discount Rate 14\%, maka diketahui jumlah PV arus manfaat kotor sebesar Rp. 85.849.588 dan jumlah PV arus biaya sebesar Rp. 67.001.856 Sehingga nilai Gross B/C Ratio yang didapat adalah sebesar 1,28 yang berarti untuksatu rupiah yang diinvestasikan akan memberikan manfaat sebesar 1,28 rupiah atau dengan kata lain manfaat yang diperoleh sebesar 1,28 kali lipat dari biaya yang dikeluarkan. Dimana nilai tersebut lebih besar dari satu $(>1)$ maka Usahatani Kopi Arabika Di Desa Bandung Baru Kecamatan Kabawetan Kabupaten Kepahiang layak untuk 
diusahakan karena dapat memberikan keuntungan atas investasi yang ditanamkan.

\section{Profitability}

Berdasarkan Tabel 1 diketahui bahwa PV Gr (B-OM) sebesar Rp.35.818.074 dan PV Invest sebesar Rp. 16.970.341 sehingga nilai Profitabiliti yang didapatkan adalah sebesar 3,8 dimana nilai ini lebih besar dari satu (>1). Maka Usahatani Kopi Arabika Di Desa Bandung Baru Kecamatan Kabawetan Kabupaten Kepahiang layak untuk diusahakan karena dapat memberikan keuntungan atas investasi yang ditanamkan

\section{Net Present Value}

Berdasarkan Tabel 1 diketahui bahwa PV arus manfaat kotor sebesar Rp. 85.849.588 dan jumlah PV arus biaya sebesar Rp. 67.001.856 dengan tingkat suku bunga (discount rate) sebesar 14\%. Sehingga hasil Net Present Value adalah Rp. 18.847.733 per musim tanam, dimana nilai tersebut lebih besar dari nol maka Usahatani Kopi Arabika Di Desa Bandung Baru Kecamatan Kabawetan Kabupaten Kepahiang layak untuk diusahakan karena dapat memberikan keuntungan atas investasi yang ditanamkan.

\section{Internal Rate of Return}

Berdasarkan Tabel 1 diketahui bahwa nilai NVP suku bunga tinggi dengan DF 14\% sebesar 18.847 .733 sedangkan NVP dengan suku bunga rendah dengan DF 13\% sebesar 20.343.291. Sehingga didapatkan nilai IRR sebesar 26,60 \% yang berarti Usahatani Kopi Arabika Di Desa Bandung Baru Kecamatan Kabawetan Kabupaten Kepahiang Akan Layak Jika IRR lebih besar dari tingkat suku bunga (discount rate) yaitu $14 \%$.

\section{Analisis Sensitivitas}

Analisis sensitivitas bertujuan untuk melihat apa yang akan terjadi dengan analisis investasi usahatani kopi arabika jika ada perubahan-perubahan dalam perhitungan biaya dan penerimaan.

Diasumsikan dalam analisis sensitivitas ada 3 aspek yang dianalisis yaitu:

a. Kenaikan biaya produksi, terutama biaya operasional.

b. Penurunan harga jual produk yang dihasilkan, sehingga akan menurunkan benefit yang diperoleh.

c. Penurunan produksi. Untuk lebih jelasnya

d. Berdasarkan Tabel 2, diketahui bahwa bila naiknya biaya produksi sampai 29\% dari kondisi saat penelitian maka Usahatani Kopi Arabika di Desa Bandung Baru Kecamatan Kabawetan Kabupaten Kepahiang tidak layak lagi 
untuk diusahakan. Hasil ini di dasarkan dari perhitungan kriteria kelayakan yang digunakan dalam penelitian ini.

e. Berdasarkan Tabel 2, pada saat harga produk turun mencapai $22 \%$ maka usahatani kopi arabika tidak layak lagi untuk diusahakan karena tidak dapat memberikan keuntungan atas investasi yang ditanamkan. Berdasarkan Tabel 2, diketahui bahwa bila produksi turun sampai 22\% maka Usahatani Kopi Arabika di Desa Bandung Baru Kecamatan Kabawetan Kabupaten Kepahiang tidak layak lagi untuk diusahakan karena tidak dapat memberikan keuntungan atas investasi yang ditanamkan.

Tabel 2. Analisis Sensitivitas Usahatani Kopi Arabika terhadap Penurunan Harga dan BiayaProduksi Naik

\begin{tabular}{|c|c|c|c|c|c|c|c|c|}
\hline \multirow{2}{*}{ No } & \multirow{2}{*}{ Keterangan } & \multicolumn{5}{|c|}{ Kriteria Investasi } & \multirow{2}{*}{$\begin{array}{c}\text { Pay back } \\
\text { Period }\end{array}$} & \multirow{2}{*}{ Kesimpulan } \\
\hline & & Net $B / C$ & Gross B/C & PV"K & NPV & IRR & & \\
\hline \multirow[t]{3}{*}{1} & Kenaikan Biaya Produksi $10 \%$ & 1,67 & $\overline{1,16}$ & 1,65 & 12.147 .547 & $23,90 \%$ & 5 thn 2 bln & Layak \\
\hline & Kenaikan Biaya Produksi 15\% & 1,47 & 1,11 & 1,40 & 8.797 .454 & $22,02 \%$ & 5 thn 3 bln & Layak \\
\hline & Kenaikan Biaya Produksi 29\% & 0,97 & 0,99 & 0,97 & $-582804,9$ & $13,19 \%$ & 5 thn $9 \mathrm{bln}$ & Tidak Layak \\
\hline \multirow[t]{3}{*}{2} & Harga Produksi Turun $10 \%$ & 1,63 & 1,15 & 1,60 & 10.262 .774 & $23,50 \%$ & 4 thn 1 bln & Layak \\
\hline & Harga Produksi Turun 15\% & 1,37 & 1,09 & 1,35 & 5.970 .294 & $20,84 \%$ & 4 thn 3 bln & Layak \\
\hline & Harga Produksi Turun $22 \%$ & 0,99 & 0,99 & 0,99 & $-39176,9$ & $13,93 \%$ & 4 thn 4 bln & Tidak Layak \\
\hline \multirow[t]{3}{*}{3} & Produksi Turun $10 \%$ & 1,63 & 1,15 & 1,60 & 10.262 .774 & $23,50 \%$ & 4 thn 1 bln & Layak \\
\hline & Produksi Turun 15\% & 1,37 & 1,09 & 1,35 & 5.970 .294 & $20,84 \%$ & 4 thn 3 bln & Layak \\
\hline & Produksi Turun 22\% & 0,99 & 0,99 & 0,99 & $-39176,9$ & $13,93 \%$ & 4 thn 4 bln & Tidak Layak \\
\hline
\end{tabular}

Sumber : Hasil Olahan data primer

\section{Analisis Payback Period}

Dalam menentukan nilai payback period pada usahatani kopi arabika di desa bandung baru kecamatan kabawetan kabupaten kepahiang, menggunakan perhitungan yang memiliki cashflow dari proyek investasi yang berbeda setiap tahun. Karena dari perhitungan cashflow usahatani kopi arabika memang memiliki cashflow berbeda pada setiap tahunnya. Sehingga dari perhitungan analisis payback period, lamanya waktu yang dibutuhkan untuk mengembalikan biaya investasi dalam usahatani kopi arabika di desa bandung baru kecamatan kabawetan kabupaten kepahiang selama 2 tahun 2 bulan. Sedangkan ketika biaya produksi naik sebesar $29 \%$ payback periodnya selama 5 tahun 3 bulan dan pada saat harga turun dan produksi turun sebesar $22 \%$ nilai payback period selama 4 tahun 4 bulan. 


\section{SIMPULAN DAN SARAN}

\section{Simpulan}

Berdasarkan hasil pembahasan yang telah di lakukan maka dapat ditarik kesimpulan sebagai berikut:

i. Usahatani Kopi Arabika yang diusahakan oleh petani di Desa Bandung Baru Kecamatan Kabawetan Kabupaten Kepahiang di lihat dari aspek financial layak untuk diusahakan. Hal ini terlihatdari nilai Net B/C Ratio sebesar 2,17 nilai Gross B/C Ratio 1,28 sebesar nilai PV" / K sebesar 2,11 nilai NVP sebesar Rp. 18.847.733dan nilai IRR sebesar 26,60 \%.

ii. Berdasarkan analisis lamanya waktu yang dibutuhkan untuk mengembalikan biaya investasi (Payback Period) adalah 2 tahun 4 bulan danan alisis sensitivitas menunjukan bahwa jika terjadi Kenaikan Biaya Produksi sebesar 20\%, Penurunan Harga sebesar 15\% dan turunnya produksi sebesar $15 \%$, maka usahatani kopi arabika tidak layak lagi untuk diusahakan karena nilai Net B/C Ratio, Gross B/C Ratio, profitability lebih kecil dari satu $(<1)$, nilai NVP lebih kecil dari nol $(<0)$ dan nilai IRR lebih kecil dari discount rate (14\%).

\section{Saran}

i. Berdasarkan hasil analisis kelayakan usahatani kopi arabika layak untuk diusahakan jika nilai dari IRR lebih besar dari suku bunga bank yang sedang berlaku yaitu $14 \%$, hal ini berdasarkan dari hasil analisis yang sudah dilakukan yaitu didapatkan nilai IRR 26,60 \%. Sedangkan jika nilai dari IRR kurang dari $14 \%$ maka akan lebih baik menyimpan uang di Bank karena lebih menguntungkan dari pada menanamkan modal dengan cara berusahatani kopi arabika.

ii. Untuk menjaga agar usahatani kopi arabika dapat berjalan dengan baik diharapkana danya campur tangan pemerintahan secara berlanjut.

\section{DAFTAR PUSTAKA}

Gittinger, J.P. 1986. Analisa Ekonomi Proyek-proyek Pertanian.Edisi kedua. Penerbit Universitas Indonesia.Jakarta

Gray, C. Simanjutak. 1993. Pengantar Evaluasi Proyek Edisi Kedua. Gramedia. Jakarta

Scheaffer, Richard L., William Mendenhall, Lyman Ott. 1990. Elementary Survey Sampling. Fourth edition. PWS Kent Publishing Company. Boston. 